\title{
CONSTITUCIONALISMO BRASILEIRO E MATRIZES DA EDUCAÇÃO NACIONAL: SUPERAÇÃO DAS TEORIAS DA SOCIEDADE DE DISCIPLINA E SOCIEDADE DE CONTROLE PARA A VIABILIZAÇÃO DA EDUCAÇÃO EMANCIPATÓRIA E AMBIENTALMENTE SUSTENTÁVEL
}

\author{
CONSTITUCIONALISMO BRASILEÑO Y MATRICES DE EDUCACIÓN: \\ SUPERACIÓN DE LAS TEORÍAS "SOCIEDAD DISCIPLINARIA" Y "SOCIEDAD \\ DE CONTROL" PARA LA VIABILIDAD DE LA EDUCACIÓN EMANCIPADORA \\ Y AMBIENTALMENTE SOSTENIBLE
}

\author{
${ }^{1}$ Anacélia Santos Rocha \\ ${ }^{2}$ Márcio Luís de Oliveira
}

\section{RESUMO}

O trabalho apresenta algumas reflexões sobre as matrizes educacionais do Brasil em dois cenários distintos do constitucionalismo nacional, procurando relacioná-las com as teorias da sociedade de disciplina de Foucault e da sociedade de controle de Deleuze. O objetivo geral é criticar os dois movimentos importantes vividos na história do ensino brasileiro e verificar alguma relação entre eles a sociedade de disciplina e a sociedade de controle e a sua incapacidade de gerar uma matriz educacional emancipatória da pessoa e ambientalmente sustentável em relação ao planeta. Para tanto, a metodologia utilizada para desenvolver o trabalho foi a da pesquisa bibliográfica descritiva.

Palavras-chave: Constitucionalismo brasileiro, Educação, Sociedade de disciplina, Sociedade de controle, Emancipação da pessoa, Sustentabilidade ambiental

\section{RESUMEN}

Este artículo presenta algunas reflexiones sobre las matrizes educativas de Brasil en dos diferentes escenarios del constitucionalismo nacional y busca relacionarlas con las teorías de la sociedad disciplinaria de Foucault e de control de Deleuze. Tiene por objetivo general criticar los dos movimientos importantes experimentados en la historia de la educación brasileña y verificar cualquier relación entre ellos - la sociedad disciplinaria y la sociedad de control - y su incapacidad para generar una matriz educativa emancipadora de la persona y ambientalmente sostenible del planeta. Por lo tanto la metodología utilizada para el desarrollo de este estudio fue la analise descriptiva.

Palabras-claves: Constitucionalismo brasileño, Educación, Sociedad disciplinaria, Sociedad de control, Emancipación de la persona, Sostenibilidad del medio ambiente

\footnotetext{
${ }^{1}$ Doutorado em andamento em Direito na Pontifícia Universidade Católica do Rio de Janeiro - PUC/Rio (Brasil). Professora na Escola Superior Dom Helder Câmara - ESDHC, Belo Horizonte - MG (Brasil).

E-mail: anacelia@ domhelder.edu.br

${ }^{2}$ Doutor em Direito pela Universidade Federal de Minas Gerais - UFMG, Belo Horizonte - MG (Brasil). Professor na Universidade Federal de Minas Gerais - UFMG, Belo Horizonte - MG (Brasil).

E-mail: marcio.luis@uol.com.br
} 


\section{INTRODUÇÃO}

O presente trabalho apresenta algumas reflexões acerca das matrizes educacionais do Brasil em contextos históricos distintamente influenciados por questões políticas e econômicas, procurando relacioná-las com a teoria da "sociedade de disciplina", de Foucault, e a da "sociedade de controle", tratada por Deleuze.

O recorte temporal concentra-se em dois períodos da história nacional: 1930 e 1990. Em ambas as décadas, aconteceram movimentos ideológicos impactantes nas esferas social, política e econômica que, em seus respectivos momentos, geraram reflexões sobre o direcionamento do sistema nacional de educação; são eles, respectivamente, o Manifesto dos Pioneiros, em 1932, e a reforma neoliberal na década de 1990.

Nesse sentido, algumas perguntas nortearam a elaboração do artigo: qual tipo de sociedade - a de "disciplina" ou a de "controle" - se faria presente em cada um desses movimentos históricos? Como esses dois modelos são insuficientes para a afirmação de uma educação emancipatória da pessoa e ambientalmente sustentável do planeta?

Estas perguntas contribuem para a delimitação dos objetivos do trabalho, cuja finalidade geral é analisar os dois movimentos importantes vividos na história do ensino brasileiro e verificar alguma relação entre eles - a sociedade de disciplina e a sociedade de controle - e a sua incapacidade de gerar uma matriz educacional emancipatória da pessoa e ambientalmente sustentável em relação ao planeta.

Como objetivos específicos analisamos, de forma crítica: a) o Manifesto dos Pioneiros e seu impacto na educação nacional; e b) a reforma neoliberal e seus desdobramentos no sistema educacional brasileiro. Em cada uma das situações, fizemos uma abordagem da matriz de ensino nacional sob a perspectiva da teoria da "sociedade de disciplina" e a da "sociedade de controle".

A metodologia utilizada para desenvolver o presente trabalho foi a pesquisa bibliográfica descritiva. Na primeira parte, discorremos sobre o Manifesto dos Pioneiros e quais foram suas orientações para as mudanças no cenário educacional. Buscamos, ainda, verificar se houve alguma relação entre o Manifesto dos Pioneiros com o que Foulcault descrevia como sendo a "sociedade disciplinar". E, na segunda parte, a pesquisa verificou o impacto da reforma neoliberal na educação e procurou estabelecer uma ligação com a teoria da "sociedade de controle" descrita por Deleuze. 
Na sua conclusão, o artigo buscou responder aos objetivos da pesquisa, demonstrando, de forma crítica, as reflexões que os dois movimentos, a seu tempo, produziram nas matrizes educacionais brasileiras.

\section{O MOVIMENTO "MANIFESTO DOS PIONEIROS”, A EDUCAÇÃO E A SOCIEDADE DE DISCIPLINA}

O Brasil possui um legado de sete Constituições; e todas, com maior ou menor densidade, tratam do tema educação, segundo as conjunturas socioeconômicas e políticas de cada sistema constitucional.

Mas, neste longo período de quase duzentos anos de constitucionalismo nacional, destacamos dois movimentos político-econômicos que repercutiram no questionamento da matriz constitucional da educação brasileira. O primeiro deles é o Manifesto dos Pioneiros da Educação Nova, na transição do sistema constitucional de 1891 para o sistema constitucional de 1934. O segundo, é o pensamento neoliberal que se desvelou na primeira década do vigente sistema constitucional.

Em 1932, a publicação de "O Manifesto dos Pioneiros da Educação Nova", por um grupo de notórios intelectuais, apresentou ao país a chamada "ideologia dos renovadores", que se aproximava da concepção liberal e idealista dos educadores do século XIX. Os signatários do Manifesto, também conhecidos como "educadores liberais", reivindicavam mudanças profundas na estrutura do ensino brasileiro, respondendo às necessidades de desenvolvimento da época (CURY, 1997, p. 43).

No contexto de transição política iniciada pelo golpe militar de 1930, o

(...) Manifesto apresenta a novidade de vislumbrar a educação como um problema social. Mas não se detém aí. Para ele, o método científico, aplicado ao estudo dos problemas educacionais, acabou gerando uma nova concepção de educação, segundo a qual é o educando, com seu interesse, suas aptidões e tendências, quem deve ser o centro da ação pedagógica. Preconiza, portanto, a mudança de métodos educacionais fundamentando seu parecer sobre as descobertas da psicologia. Foi analisando a educação, do ponto de vista filosófico, sociológico e psicológico, que o Manifesto fundamentou as reivindicações de mudança que suscitou em prol da educação escolar brasileira. (ROMANELLI, 2002, p. 146) 
Dessa forma, o movimento revelou-se avançado para a época e posicionou-se diferentemente das reformas anteriores, que eram pensadas e implementadas sem considerar os problemas e aspectos globais da educação como propulsora da emancipação da pessoa, numa sociedade laica. Nesse sentido, o Manifesto mostrou-se inovador, pois

\begin{abstract}
(...) sugere em que deva constituir a ação do Estado, reivindicando a laicidade do ensino público, a gratuidade, a obrigatoriedade e a co-educação.

Reconhecendo pertencer ao cidadão o direito vital à educação, e ao Estado o dever de assegurá-la de forma que ela seja igual e, portanto, única, para todos quantos procurarem a escola pública (...) é evidente que esse direito só possa ser assegurado a todas as camadas sociais, se a escola for gratuita. (ROMANELLI, 2002, p. 147)
\end{abstract}

Ademais, ao posicionar o educando no centro do processo de ensino, o movimento afastava a política educacional dos preconceitos e ideologias que pudessem influenciar negativamente o aprendizado, de modo a fomentar a emancipação do educando, o que era, em síntese, o objetivo principal do Manifesto. Assim,

\begin{abstract}
(...) a necessidade de colocar o "ambiente escolar acima das seitas, disputas religiosas, de dogmatismo" e de excluir do mesmo qualquer "influência perturbadora à personalidade do educando", impõe-se que seja leigo o ensino, na escola pública (...) E, finalmente, decorrente do direito de todos à educação, está o direito de ambos os sexos às mesmas oportunidades devendo a ação pedagógica obedecer a diferenças pedagógicas de ordem geral e não às de ordem sexual. A co-educação põe em pé de igualdade, quanto à qualidade da educação, os educandos de ambos os sexos. (ROMANELLI, 2002, p. 148)
\end{abstract}

Portanto, o Manifesto defendia a educação como direito individual e universal e de responsabilidade do Estado, que deveria viabilizá-lo por meio da acessibilidade à escola pública gratuita e leiga.

Naquela conjuntura histórica, a "ideologia dos renovadores" tratou da educação como um problema social relevante e de interesse público, opondo-se, por conseguinte, à précompreensão da então vigente política de "educação-privilégio", que orientava a matriz educacional brasileira desde o período colonial.

Como todo movimento histórico, o Manifesto estava inserido em um contexto social, político e econômico em efervescência: uma série de movimentos $\operatorname{armados}^{1}$ que eclodiam por todo o país, gerando rompimentos políticos e econômicos com a oligarquia que governava o

\footnotetext{
1 A década de 1920 foi um período de várias revoltas armadas, dentre as quais destaca-se o Tenentismo, por ter provocado maior impacto nas reivindicações por mudanças no processo político.
} 
Estado. A situação, que foi agravada pela crise econômica de 1929, resultou na queda do preço do café - nosso principal produto de exportação - no mercado internacional e gerou um forte desequilíbrio da balança comercial brasileira.

A instabilidade social, política e econômica levou ao golpe de Estado de 1930, que conduziu Getúlio Vargas à chefia de um longo governo de exceção.

Por outro lado, a acumulação primitiva de capital e a ampliação crescente do mercado consumidor interno possibilitaram ao Brasil uma reação e guinada rumo à industrialização, cujo processo foi progressivamente acelerado a partir daquele período de transição. Em síntese,

\section{A economia brasileira reagia de forma dinâmica aos efeitos da crise: o crescimento do mercado interno e a queda das exportações implicaram a transferência da renda de um setor para o outro. Essa transferência se fez do setor tradicional para o moderno, ou seja, da área agrícola para a industrial (ROMANELLI, 2002, p. 48)}

Logo, a crise desenhou-se como uma necessidade imperativa de ajustamento no aparelho do Estado frente às novas demandas da economia e da política nacional. E, naquele bojo, a escola foi posta pelo Manifesto como um espaço significativo de formação de pessoas solidárias, respeitosas e cooperativas, bem como preparadas para o trabalho. Consequentemente, o indivíduo precisava ser educado para a vida em sociedade.

Como ressalta Azevedo,

A cada época, na marcha da civilização, correspondem processos novos de educação
para uma adaptação constante às novas condições da vida social e à satisfação de suas
tendências e de suas necessidades. As ideias e as instituições pedagógicas são
essencialmente "o produto de realidades sociais e políticas". (AZEVEDO, 1932, p. 25)

A educação foi, então, considerada uma "variável chave" na política de alfabetização e de civilização do povo brasileiro, preparando o estudante para as demandas do país em relação à matriz ideológica e econômica que se implementava no período de transição do regime oligárquico para a Era Vargas. Segundo Anísio Teixeira (2000), signatário do movimento, a escola formaria o indivíduo para a vida. No ambiente educacional, seria forjado o homem bondoso, gentil e tolerante, conforme os princípios liberais; um indivíduo que buscasse liberdade, riqueza e harmonia, impulsionado pela industrialização. Consagrava-se aí a nova plataforma de desenvolvimento socioeconômico: o modelo burguês.

Ressalta-se que, em termos nacionais, o manifesto era, de início, avançado para os anos de 1930, uma vez que o Brasil estava muito atrasado na contextualização histórica do liberalismo ocidental. 
Contudo, como lembra Foucault, o lema liberal do homem bondoso, gentil e tolerante era, em verdade,

(...) uma redução materialista da alma e uma teoria geral do adestramento, no centro dos quais reina a noção de "docilidade" que une ao corpo analisável ao corpo manipulável. É dócil um corpo que pode ser submetido, que pode ser utilizado, que pode ser transformado e aperfeiçoado. (FOUCAULT, 2012, p. 132)

De fato, o conceito liberal de "corpos dóceis“, em evidência nos séculos XVII e XVIII, transformou a política educacional num método disciplinar que, na verdade, se desvelava em fórmulas gerais de dominação (FOUCAULT, 2012, p. 133). A “sociedade de disciplina” surge, pois,

\begin{abstract}
(...) no momento em que nasce uma arte do corpo humano, que visa não unicamente o aumento de suas habilidades, nem tampouco aprofundar sua sujeição, mas a formação de uma relação que no mesmo mecanismo o torna tanto mais obediente quanto é mais útil, e inversamente. Forma-se uma política das coerções que são um trabalho sobre um corpo, uma manipulação calculada de seus elementos, de seus gestos, de seus comportamentos (...) se a exploração econômica separa a força e o produto do trabalho, digamos que a disciplinar estabelece no corpo o elo coercitivo entre uma aptidão aumentada e uma dominação acentuada. (FOUCAULT, 2012, p. 134)
\end{abstract}

Constata-se, portanto, que a ideologia educacional que se apresentava como avançada para a época era apenas um movimento anacrônico de alguns prestigiados intelectuais. De qualquer modo, e por motivos políticos diversos daquele período de transição entre dois sistemas constitucionais historicamente entremeados por um governo de exceção (o governo provisório de Getúlio Vargas), a ideologia divulgada no Manifesto dos Pioneiros da Educação Nova não chegou a ser positivada no sistema jurídico brasileiro.

Contudo, e muito embora a ideologia já tivesse sido superada na Europa ocidental, o Manifesto dos Pioneiros da Educação Nova contribui para produzir as primeiras reflexões significativas acerca da educação nacional e seu papel na emancipação do educando, ainda que sob o paradigma da sociedade de disciplina.

\title{
3. O MOVIMENTO NEOLIBERAL, A EDUCAÇÃO E A SOCIEDADE DE CONTROLE
}

Transcorrido mais de meio século do Manifesto dos Pioneiros da Educação Nova, o processo constituinte que culminou na positivação da Constituição de 1988 revelou-se bem mais consciente da acentuada desigualdade social no Brasil, além de demonstrar real compromisso com os valores da democracia plural e inclusiva e com o socioambientalismo. Como corolário, a educação foi incluída entre os direitos sociais (art. $6^{\circ}$ e arts. 205 a 214, da CRFB) e a promoção 
da educação ambiental em todos os níveis de ensino foi prevista no art. 225 , $\S 1^{\circ}$, inc. VI, da Constituição.

Para Silva (2010, p. 865) a previsão constitucional da promoção da educação para a sustentabilidade ambiental tem natureza de norma programática e intergeneracional, sobretudo em relação ao futuro. Portanto, as ações do Estado, em parceria com a iniciativa privada, em prol do fomento da educação focada na sustentabilidade têm por finalidade a formação de uma cidadania ambientalmente consciente de suas práticas individuais e coletivas. Tal conscientização tem a potencialidade para gerar responsabilidade e solidariedade a favor da preservação do meio ambiente e do desenvolvimento sustentável. Logo, ainda que seja uma norma programática, o dispositivo constitucional em comento demanda alterações substanciais nos currículos e nas práticas escolares em todos os graus da educação nacional. E não se trata de um comando constitucional direcionado apenas ao ensino formal, mas também na veiculação de informações e de boas práticas públicas e privadas que possam ser disseminadas entre os diversos segmentos da sociedade.

Assim, Silva afirma que

Promover a educação ambiental em todos os níveis de ensino e a conscientização pública para a preservação do meio ambiente, como quer o inciso VI do $\S 1^{\circ}$ do art. 225 da $\mathrm{CF}$, constitui providência que propiciará, no futuro, o exercício de práticas conscientemente preservacionistas. (SILVA, 2010, p. 865)

Percebe-se, portanto, que o nosso sistema constitucional estimula, em suas origens, uma sinergia entre a emancipação da pessoa e a proteção do meio ambiente na agenda governamental para a educação, atuando, pois, em plena consonância com as diretrizes adotadas pela sociedade internacional a partir da Conferência de Estocolmo, de 1972. Ao abordar o tema, Silva esclarece que aquela Conferência refletiu "as discussões [que] ocorreram entre os países industrializados e os não industrializados, levando-se em consideração os aspectos relacionados à poluição atmosférica, desenvolvimento econômico e industrialização" (SILVA, 2012, p. 67)

O sistema constitucional inova, ainda, ao atribuir à União, aos Estados, aos Municípios e ao Distrito Federal a competência para legislar concorrentemente sobre educação e meio ambiente (CRFB, art. 24, incisos VI, VIII e IX, e art. 30, incisos I e II). Ademais, a Constituição confere a todos os entes internos da Federação a competência comum para a implementação de políticas de proteção do meio ambiente e de educação, observadas as prioridades de cada ente quanto aos níveis de ensino (CRFB, art. 23, incisos V, VI e VII). 
Cury esclarece que, no sistema constitucional iniciado em 1988,

(...) o ensino fundamental, gratuito e obrigatório, ganha condição de direito público subjetivo para todos, os sistemas de ensino passam a coexistir em regime de colaboração recíproca, a gestão democrática torna-se princípio dos sistemas públicos de ensino e a gratuidade, em nível nacional e para todos os níveis e etapas da escolarização pública se torna princípio de toda a educação nacional. $O$ texto constitucional reconhece o direito à diferença de etnia, de idade, de sexo e situações peculiares de deficiência”. (CURY, 2005, p. 57)

E por ser inerente ao processo de inclusão social e de formação plural das identidades individuais e coletivas, a educação passa a integrar, por consequência, os objetivos fundamentais do Estado Democrático de Direito previstos no artigo $3^{\circ}$ da Constituição; objetivos que devem ser permanentemente perseguidos e atualizados pela sociedade, pela iniciativa privada e pelo Estado:

I - Construir uma sociedade livre, justa e solidária;

II - Garantir o desenvolvimento nacional;

III - Erradicar a pobreza e a marginalização e reduzir as desigualdades sociais e regionais;

IV - Promover o bem de todos, sem preconceitos de origem, raça, cor, sexo, idade e quaisquer outras formas de discriminação.

Sabe-se que todos os dispositivos constitucionais focados nos objetivos a serem alcançados pelo Estado e pela sociedade brasileira assentam-se na promoção de direitos, garantias e deveres fundamentais. No caso em análise, são direitos de quarta e de quinta geração que demandam por efetivação também por via de projetos de educação e de conscientização:

Os direitos e garantias da quarta dimensão dizem respeito a demandas de amplitude global, envolvendo, consequentemente, os interesses de todos os povos da Terra. São demandas como a paz e a segurança mundiais, o desenvolvimento sustentável, o pluralismo social e a democracia, a preservação do planeta, a implementação de políticas humanitárias, a distribuição menos desigual da renda e um comércio internacional mais justo. Tal dimensão se funda na necessidade de 'cooperação' e de 'integração' entre todos os segmentos e instâncias de poder social, econômico e político em âmbitos nacionais e internacional, de modo a viabilizar a afirmação de uma juridicidade consensualmente universal que possa ser capaz de proteger a dignidade humana e de respeitar a multiplicidade cultural dos povos, em escala global.

(...)

(...) os avanços da engenharia genética trouxeram para o plano dos direitos, garantias de deveres fundamentais a questão do chamado 'Biodireito'. Assim, os direitos, garantias e deveres da quinta dimensão dizem respeito à proteção do patrimônio genético da humanidade e da biodiversidade, contra a manipulação científica indevida, nos setores público e privados. (...)

Logo, os direitos e garantias fundamentais de quinta dimensão se apoiam no princípio da eticidade das atividades humanas como pressuposto para a positivação jurídica de princípios e regras que possam nortear a atividade científica, em especial a atividade que tenha potencialidade danosa à continuidade da vida, como as pesquisas genéticas e os experimentos com material nuclear. (OLIVEIRA, 2013, p. 138-140) 
Percebe-se, pois, que a educação assume, na vigente Constituição, uma função primordial na construção da cidadania em suas múltiplas dimensões, como a conscientização ambiental entre as gerações. Para tanto, a Constituição também instituiu um regramento detalhado sobre a educação em seus diferentes níveis (artigos 205 a 214). Assim, no plano normativo constitucional, foram estabelecidas as diretrizes básicas das políticas educacionais a serem democraticamente reguladas e implementadas por todos os entes da Federação, havendo ainda a determinação constitucional específica de percentuais financeiro-orçamentários mínimos a serem compulsoriamente aplicados pela União, Estados-Membros, Municípios e Distrito Federal na educação (art. 212). E de modo a viabilizar as diretrizes constitucionais da educação pelos entes internos da federação, a União, em 1996, editou a Lei de Diretrizes e Bases da Educação Nacional - LDBEN (Lei no 9.394).

Entretanto, na década de 1990, o movimento reformista neoliberal introduzido na política econômica significou a passagem do rígido modelo fordista - até então parcialmente adotado no Brasil - para a matriz flexível de acumulação, o que gerou, dentre outras consequências, a abertura do processo de produção, a relativização do mercado de trabalho e a massificação do consumo. A alternância do pensamento econômico teve enorme impacto em todos os segmentos da sociedade, e com significativa alteração da política educacional brasileira, como relata Rocha:

\begin{abstract}
O movimento reformista constituiu-se como uma ofensiva internacional, concernente a todos os domínios e níveis de formação, vinculada ao conteúdo educativo e às formas de avaliação. O que se debate é que a educação, do ponto de vista das trocas internacionais, gradualmente deixe de ser um domínio específico que depende exclusivamente da ação do Estado (pois ele não deve constituir um entrave às trocas e à livre concorrência, mas, ao contrário, tem a responsabilidade de fazer respeitar o livre jogo do mercado etc., conservando e reforçando sua função de mantenedor da ordem e de segurança). (ROCHA, 2004, p. 166)
\end{abstract}

A partir de então, o neoliberalismo passa a ser também a nova matriz política brasileira, e a diretriz educacional fica dependente da reforma estrutural do Estado. Em nota crítica, Bonavides afirma que a partir do momento em que um país passa a adotar uma política neoliberal

Já não se fala de sociedade de classes, de burgueses ou proletários, de hiatos sociais consagrados na linguagem das ideologias, mas de sociedades de consumidores no mercado da globalização, onde a cidadania é a irrisão, ou o substantivo que perdeu o ethos político de suas origens. (BONAVIDES, 2001, p. 187) 
No que concerne aos impactos do neoliberalismo na educação, interessante mencionar que, até mesmo nos Estados Unidos, nos anos de 1990, o Ministério do Trabalho daquele país elaborou relatório com orientações a serem consideradas pelas escolas com a finalidade de atender às necessidades do mercado. $\mathrm{O}$ relatório

(...) determina que os ensinos fundamental e médio deverão fornecer aos alunos uma estrutura de capacitação básica, cognitiva e de qualidades pessoais que consistiriam em: ler, escrever, contar, calcular, escutar, falar, pensar, criativamente, tomar decisões, solucionar problemas, perceber com acuidade, saber como aprender e raciocinar, responsabilidade, auto-estima, sociabilidade, autogerenciamento, integridade e honestidade, além de competências e habilidades (skills) tão importantes quanto os conhecimentos técnicos e intelectuais, mas distintas destes - essas competências representam os atributos que o empregador de alto desempenho de hoje procura no funcionário de amanhã, pois as próprias escolas precisam ser convertidas em organizações de alto desempenho, tal como os indivíduos e as empresas. (ROCHA, 2004, p. 156)

O trabalho em grupo, característica fundamental para o funcionário do futuro, passou a ser incentivado nas escolas por novas tendências pedagógico-psicológicas (ROCHA, 2004).

No Brasil, e independentemente da matriz neoliberal, o fundamento jurídico para o atrelamento da educação ao mercado de trabalho encontra-se na própria Constituição, em seu artigo 205:

A Educação, direito de todos e dever do Estado e da família será promovida e incentivada com a colaboração da sociedade visando ao pleno desenvolvimento da pessoa, seu preparo para o exercício da cidadania e sua qualificação para o trabalho (grifo nosso).

Assim, no contexto socioeconômico do consumo de massa, seríamos, a princípio, educados para viver na sociedade de disciplina analisada por Foulcault:

Esse é o tempo disciplinar que se impõe pouco a pouco à prática pedagógica especializando o tempo de formação e destacando-o do tempo adulto, do tempo do ofício adquirido; organizando diversos estágios separados uns dos outros por provas graduadas; determinando programas, que devem se desenrolar cada um durante determinada fase, e que comportam exercícios de dificuldade crescente; qualificando os indivíduos de acordo com a maneira como percorrem essas séries. (FOUCAULT, 2012, p. 153)

Entretanto, para Deleuze (1992), não estamos mais na sociedade de disciplina que funcionava por confinamento; estamos entrando na sociedade de controle cujo procedimento se dá através do controle contínuo da comunicação instantânea, pois “o que está sendo implantado, às cegas, são novos tipos de sanções, de educação, de treinamento". (DELEUZE, 1992, p. 220). 
No caso da educação, o autor é categórico ao afirmar que a reforma escolar é uma ilusão, pois

\begin{abstract}
Pode-se prever que a educação será cada vez menos um meio fechado distinto do meio profissional - um outro meio fechado -, mas que os dois desaparecerão em favor de uma terrível formação permanente, de um controle contínuo se exercendo sobre o operário-aluno ou executivo-universitário. (DELEUZE, 1992, p. 220)
\end{abstract}

Deleuze sugere que o que está por vir é algo que fará com que a sociedade de disciplina não pareça tão ruim, pois, "na sociedade de controle nunca se termina nada" (DELEUZE, 1992, p. 220). O autor insiste que, diante das "formas próximas de controle incessante em meio aberto, é possível que os confinamentos mais diretos nos pareçam pertencer a um passado delicioso e benevolente". (DELEUZE, 1992, p. 220)

O filósofo afirma que o mundo encontra-se numa crise generalizada de todos os meios de confinamento (disciplina): prisão, hospital, escola, fábrica, família. Essa crise é usada no meio político para a promessa de "reformas". Entretanto, o que pontuaremos a seguir é a transformação no modo de controle dos espaços, das máquinas, das atividades, dos processos, das instituições, dos indivíduos, do mercado, do capitalismo.

Há uma mudança em curso que perpassa todas as instituições, especialmente as de educação. Aquelas instituições que, no passado, utilizaram de métodos de disciplina (confinamento) para obter o controle da sociedade estão, atualmente, sendo, elas próprias, influenciadas por formas de controle ilimitados. O espaço privado de convivência deixa de ser lastreado nas relações humanas e passa a ser indefinidamente aberto e monitorado pela indeterminação de sujeitos e de instituições. Já o espaço público é aquele da massificação irrefletida de comportamentos sociais, políticos e econômicos. Nesse contexto, a ciência e a tecnologia - móbiles importantes da educação - também passam por mudanças velozes:

\footnotetext{
A cada tipo de sociedade, evidentemente, se faz corresponder um tipo de máquina: as máquinas simples ou dinâmicas para as sociedades de soberania, as máquinas energéticas para as sociedades de disciplina, as cibernéticas e os computadores para as sociedades de controle. (DELEUZE, 1992, p. 220)
}

Deleuze, ressalta que os confinamentos são moldes, ao passo que os controles são modulações imperceptíveis na operacionalidade e na "alma" das instituições (DELEUZE, 1992, 225). Um exemplo interessante apresentado pelo autor é, hoje, o "salário" simbolicamente pago ao empregado pela empresa: 
(...) a fábrica era um corpo que levava suas forças internas a um ponto de equilíbrio, o mais alto possível para a produção, o mais baixo possível para os salários; mas numa sociedade de controle a empresa substituiu a fábrica, e a empresa é uma alma, um gás. Sem dúvida a fábrica já conhecia o sistema de prêmios, mas a empresa se esforça mais profundamente em impor uma modulação para cada salário, num estado de perpétua metaestabilidade, que passa por desafios, concursos e colóquios extremamente cômicos. (DELEUZE, 1992, p. 225)

Na sociedade de disciplina, Deleuze (1992) explica que a fábrica enquadrava os indivíduos em um só corpo, o que facilitava que fossem vigiados, mas na sociedade de controle, a empresa usa a competitividade entre os funcionários, causando o tempo todo uma "rivalidade inexpiável como sã emulação, excelente motivação que contrapõe os indivíduos entre si e atravessa cada um, dividindo-o em si mesmo" (DELEUZE, 1992, p. 225).

Além do estímulo incessante à competitividade, outro princípio modulador é o salário por mérito, o qual impacta, igualmente, o sistema escolar nas sociedades de controle. $\mathrm{O}$ autor afirma que

O princípio modulador do salário por mérito tenta a própria educação nacional: com efeito, assim como a empresa substitui a fábrica, a formação permanente tende a substituir a escola, e o controle contínuo substitui o exame. Esse é o meio mais garantido de entregar a escola à empresa. (DELEUZE, 1992, p. 255)

Assim, o fomento exagerado da competitividade entre os funcionários e o salário por mérito são dois princípios modeladores da sociedade de controle, os quais fazem parte de uma engrenagem inexaurível de incompletude de processos comportamentais:

Nas sociedades de disciplina não se parava de recomeçar (da escola à caserna, da caserna à fábrica), enquanto nas sociedades de controle nunca se termina nada, a empresa, a formação, o serviço sendo os estados metaestáveis e coexistentes de uma mesma modulação, como que de um deformador universal. (DELEUZE, 1992, p. 225)

Na sociedade de controle o principal instrumento de controle é a cifra:

A cifra é uma é senha, ao passo que as sociedades disciplinares são reguladas por palavra de ordem (tanto do ponto de vista da integração, quanto da resistência). A linguagem numérica do controle marca o acesso à informação, ou à rejeição. Não se está mais diante do par massa-indivíduo. Os indivíduos tornaram-se "dividuais", divisíveis, e as massas tornaram-se amostras, dados, mercados ou "bancos”. (DELEUZE, 1992, p. 226)

Nesse cenário de mudança, até o dinheiro passa a ter outro sentido:

É o dinheiro que talvez melhor exprima a distinção entre as duas sociedades, visto que a disciplina sempre se referiu a moedas cunhadas em ouro - que servia de medida padrão -, ao passo que o controle remete a trocas flutuantes, modulações que fazem intervir como cifra uma percentagem de diferentes amostras de moeda. (DELEUZE, 1992, p. 226) 
E, assim, nesse cenário de trocas flutuantes, diferente do cenário de equilíbrio, o homem também se modifica. "O homem da disciplina era um produtor descontínuo de energia, mas o homem do controle é antes ondulatório, funcionando em órbita, num feixe contínuo". (DELEUZE, 1992, p. 227)

O controle é de curto prazo e de rotação rápida, mas também contínuo e ilimitado, ao passo que a disciplina era de longa duração, infinita e descontínua. $\underline{\mathrm{O} \text { homem não é }}$ mais o homem confinado, mas o homem endividado. (DELEUZE, 1992, p. 228) (grifo nosso)

Enfim, todas as diferenças citadas acima entre a sociedade da disciplina e a sociedade de controle servem para demonstrar como as estruturas de poder operam distintamente sobre a sociedade, utilizando-se de perspectivas e métodos simbólicos de educação intergeracional. Além disso, podemos facilmente perceber que estamos saindo de um padrão e ingressando em outro sem que as estruturas e funções de poder político e econômico deixem de se impor silenciosamente sobre a sociedade. Mas, em ambas, a educação continua ocupando função central na formação do indivíduo e da intersubjetividade, e sempre de modo a manter as estruturas e as funções desse mesmo poder que é capaz de se adaptar às suas próprias demandas (DELEUZE, 1992, p. 229).

No regime das escolas [prevalecem] as formas de controle contínuo, a avaliação contínua, e a ação da formação permanente sobre a escola, o abandono correspondente de qualquer pesquisa na Universidade, a introdução da "empresa" em todos os níveis de escolaridade (DELEUZE, 1992, p. 229)

Confirmando Foucault e Deleuze, Althusser (1980), explica como a escola serve de instrumento de reprodução da qualificação da força de trabalho no regime capitalista:

Ao contrário do que ocorria nas formações escravistas e servis, esta reprodução da qualificação da força de trabalho tende (trata-se de uma lei tendencial) a dar-se não mais no "local de trabalho" (a aprendizagem na própria produção) porém, cada vez mais, fora da produção, através do sistema escolar capitalista e de outras instâncias e instituições. (ALTHUSSER, 1980, p. 51)

Apesar de o capitalismo ter modificado substancialmente o seu formato nas últimas décadas, o poder econômico-político, tanto nas sociedades de disciplina como nas sociedades de controle, usa a escola para se manter e se desenvolver, por intermédio de estratégias de controle, marketing e competitividade:

(...) o capitalismo do século XIX é de concentração, para a produção e de propriedade (...), mas atualmente é um capitalismo de sobreprodução. Não compra mais matériaprima e já não vende produtos: compra produtos acabados, ou monta peças destacadas. O que ele quer vender são serviços e o que quer comprar são ações. Já não é um capitalismo dirigido para a produção, mas para o produto, isto é, para a venda ou para o mercado. Por isso esse é essencialmente dispersivo, e a fábrica cedeu lugar à empresa. (DELEUZE, 1992, p. 228) (grifo nosso) 
A necessária sinergia em torno da emancipação da condição humana e da proteção ambiental, de modo a produzir um desenvolvimento socioeconômico autossustentável das sociedades contemporâneas, só poderá ser fomentada por intermédio de uma ética que interfira e modifique as políticas públicas de educação, e que, por consequência, sejam capazes de produzir novos conhecimentos filosófico-reflexivos, científicos e tecnológicos voltados para viabilizar o bem-estar do indivíduo, da coletividade e do planeta (OLIVEIRA, 2014, p. 42).

Contudo, e ainda que o termo seja vago e permita pluralidade semântica, as múltiplas noções acerca do "desenvolvimento sustentável" vêm, ainda que timidamente, estabelecendo critérios críticos das atuais relações de poder econômico-político que se impõem sobre as sociedades e nas suas relações com o planeta. Entretanto, as novas gerações, na grande maioria dos países, e em especial no Brasil, ainda não começaram a adquirir conscientização ambiental nos primeiros anos de educação, o que tem dificultado a profusão e a afirmação de uma cultura holística que se assente em relações humanas emancipatórias e ambientalmente sustentáveis, conforme desejado pelo constituinte (OLIVEIRA, 2014, p. 42).

Ao abordar a educação como elemento impulsionador de uma nova ética não só emancipatória da pessoa mas também ambientalmente sustentável, Loureiro é bastante enfático ao dizer que:

A falta de percepção da Educação Ambiental como processo educativo, reflexo de um movimento histórico, produziu uma prática descontextualizada, voltada para a solução de problemas de ordem física do ambiente, incapaz de discutir questores sociais e categorias teóricas centrais da educação. (LOUREIRO, 2012, p. 89)

Enfim, vamos, aos poucos, percebendo que estamos na sociedade de controle na qual a escola segue seu papel de coadjuvante na implementação de um sistema perverso de poder econômico-político. Um sistema extremamente forte que consegue desconsiderar e até mesmo funcionar de forma paralela a todo o aparato jurídico - constitucional ou infraconstitucional -, ignorando-o e deixando para trás o ideário do projeto da educação para a emancipação da pessoa e para a sustentabilidade do planeta.

\section{CONSIDERAÇÕES FINAIS}

Os dois momentos históricos resgatados pela pesquisa foram fundamentais no desenho da atual matriz educacional brasileira.

No que se refere ao período de 1930, e especificamente ao movimento do Manifesto dos Pioneiros da Educação Nova, percebemos, ali, os elementos necessários para termos uma 
educação de qualidade, pública, gratuita e universal. A formação dos professores também foi levada em consideração, bem como as questões administrativas. Apesar do avanço que essas propostas representavam para o Brasil daquela época, vimos que as demandas do Manifesto estavam presentes também em situações já experimentadas na Europa, por exemplo, e que não foram apropriadas para a educação a que se almejava, qual seja, a que pudesse promover a emancipação da pessoa.

Ao contrário, o que se desenhava, apesar de avançado para aquele período, era o condicionamento para se obter "corpos dóceis", uma vez que o trabalho foi tido pelo Manifesto como uma importante atividade educativa capaz de formar indivíduos cultos e úteis. A pedagogia estimulada pelo Manifesto mostrou-se, na verdade utilitarista para um Brasil cuja economia industrializada estava ainda em seus primórdios:

(...) A escola nova, que tem que obedecer a esta lei, deve ser reorganizada de maneira que o trabalho seja seu elemento formador, favorecendo a expansão das energias criadoras do educando, procurando estimular-lhe o próprio esforço como o elemento mais eficiente em sua educação e preparando-o com o trabalho em grupos e todas as atividades pedagógicas e sociais, para fazê-lo penetrar na corrente do progresso material e espiritual. (MANIFESTO DOS PIONEIROS DA ESCOLA NOVA, 1932, p. 56) (grifo nosso)

$\mathrm{Na}$ escola, os alunos assimilariam conteúdos de maneira sistematizada, de forma a conseguir responder às demandas sociais e econômicas da época.

Nesse sentido, percebemos a similaridade com as orientações existentes na sociedade de disciplina descrita por Foucault. Só que o autor analisa procedimentos vivenciados na Europa dos séculos XVII e XVIII. Daí o estranhamento e o caráter anacrônico do Manifesto: estávamos pensando em algo apenas aparentemente inovador, em 1932, mas que já havia sido desconsiderado pelos europeus há mais de um século.

Então, apesar de o Manifesto dos Pioneiros da Educação Nova não ter sido positivado na Constituição e nem na legislação infraconstitucional, ele foi um marco importante e inspirou alterações $^{2}$ significativas no cenário educacional. Entretanto, seu atrelamento ao mercado de trabalho pelo compromisso imperativo em formar mão de obra diminuiu seu avanço por se desviar da educação para a emancipação.

\footnotetext{
2 Inspirou, por exemplo a garantia de igualdade de oportunidades educacionais que foi positivada na Constituição de 1934.
} 
Mas, seguindo em nossa história, sessenta anos depois do movimento de 1932, com a Constituição de 1988 - também chamada de "Constituição Cidadã - e com a Lei de Diretrizes e Bases para a Educação Nacional, de 1996, nos deparamos com o movimento políticoeconômico que caracterizou a década de 1990: o neoliberalismo.

Naquele cenário educacional, a matriz político-econômica assumida pelo Brasil e o mercado de trabalho que ela fomentou constituíram variáveis decisivas para os (des)caminhos do ensino.

A diferença, segundo Deleuze, é que já não vivemos mais na sociedade de disciplina, e sim na sociedade de controle. E, novamente, ao analisarmos algumas variáveis na educação, percebemos a nossa identificação com esta sociedade, nas quais as instituições estão em crise e a escola, longe de contribuir para afirmação do ideário de emancipação da pessoa e de sustentabilidade ambiental, serve para a manutenção de estruturas de poder político e econômico focadas eminentemente na autorreferencialidade do próprio poder, e que estão totalmente desconectadas das novas demandas existenciais da humanidade.

Concluímos que, se conhecemos as características e as consequências dos dois tipos de sociedade (a de disciplina e a de controle), bem como das matrizes de educação por elas produzidas (educação limitada, elitista e de treinamento apenas para o mercado de trabalho), faz-se premente que busquemos novas reflexões e propostas efetivas para construir e implementar a educação emancipatória e ambientalmente sustentável.

E isso poderá ser feito sem incorrermos no erro de desconsiderar as variáveis de uma sociedade capitalista, plural, complexa e dinâmica mas que, simultaneamente, seja capaz de gerar estruturas e dinâmicas que possam equilibrar os aspectos materiais e "espirituais" das relações humanas em suas dimensões intersubjetivas e ambientais. 


\section{BIBLIOGRAFIA}

ALTHUSSER, Louis. Posições II. Rio de Janeiro: Ed. Graal, 1980.

AZEVEDO, Fernando de. Introdução ao Manifesto dos Pioneiros da Educação Nova.

In: A reconstrução educacional no Brasil: ao povo e ao governo - Manifesto dos Pioneiros da Educação Nova (1932). São Paulo: Companhia Editora Nacional, 1932, p. 7-30.

BONAVIDES, Paulo. Do país constitucional ao país neocolonial: a derrubada da Constituição e a recolonização pelo golpe de Estado institucional. São Paulo: Malheiros Editores, 2001.

BRASIL. Constituição da República Federativa do Brasil. 48.ed. São Paulo: Saraiva. 2013.

BRASIL: Lei de Diretrizes e Bases da Educação Nacional - Lei nº 9.349, de 1996.

CITTADINO, Gisele. Pluralismo, Direito e Justiça Distributiva. Rio de Janeiro: Lúmen Júris, 1998.

CHAUÍ, Marilena. A universidade operacional. Jornal Fola de São Paulo, São Paulo, Caderno Mais, 9 de maio de 1999.

CURY, Carlos Roberto; HORTA, José Silvério; BRITO, Vera Lúcia. Medo à liberdade e compromisso democrático: LDB e Plano Nacional de Educação. São Paulo: Editora do Brasil, 1997.

CURY, Carlos Roberto. Os Fora de Série na Escola: Campinas: Associados, 2005.

DELEUZE, Gilles. Conversações. Tradução de Peter Pál Pelbart. São Paulo: Ed. 34, 1992.

FOUCAULT, M. Vigiar e Punir: Nascimento da prisão. Tradução de Raquel Ramalhete. 40.ed. Petrópolis: Vozes, 2012.

LOUREIRO, Carlos Frederico Bernardo. Trajetória e Fundamentos da Educação Ambiental. São Paulo: Editora Cortez, 2012.

MANIFESTO DOS PIONEIROS DA EDUCAÇÃO NOVA (1932). In: A reconstrução educacional no Brasil: ao povo e ao governo - Manifesto dos Pioneiros da Educação Nova (1932). São Paulo: Companhia Editora Nacional, 1932, p. 31-75.

OLIVEIRA, Márcio Luís de. Amazônia: um bem comunal, p. 42-47. In: DIZ, Jamile Bergamaschine Mata (organizadora). Nova ordem ambiental internacional e desenvolvimento sustentável. Belo Horizonte: Arraes, 2014.

OLIVEIRA, Márcio Luís de. A Constituição juridicamente adequada; transformações do constitucionalismo e atualização principiológica dos direitos, garantias e deveres fundamentais. Belo Horizonte: Arraes, 2013. 
ROCHA, Maurício de Albuquerque: Paradoxo da formação: servidão voluntária e liberação. Revista Brasileira de Educação - Anped. Editora Autores Associados: São Paulo. No 27 - Set /Out /Nov /Dez 2004.

ROMANELLI, Otaíza de Oliveira: História da Educação no Brasil. 27ª ed. Petrópolis: Vozes, 2002.

SILVA, Rodrigo Zouain da. Os desafios do direito ambiental no limiar do século XXI diante da ineficácia do sistema jurídico ambiental brasileiro. Revista Veredas do Direito. Belo Horizonte, vol. 9, n. 18, p. 57-87, jul/dez. 2012.

SILVA, José Afonso da. Comentário contextual à Constituição. São Paulo: Malheiros, 2010.

TEIXEIRA, Anísio. Pequena introdução à filosofia da educação: escola progressiva, ou a transformação da escola. Rio de Janeiro: DP\&A, 2000. 